\title{
Effective preparation of nitrogen-doped activated carbon by aniline thermal chemical vapor deposition for arsenate adsorption
}

\author{
Pyunghwa Yoo $^{1^{\dagger}}$, Yoshimasa Amano ${ }^{2,3}$, Motoi Machida ${ }^{2,3}$ \\ ${ }^{1}$ Graduate School of Science and Engineering, Chiba University, 1-33 Yayoi-cho, Inage-ku, Chiba 263-8522, Japan \\ ${ }^{2}$ Graduate School of Engineering, Chiba University, 1-33 Yayoi-cho, Inage-ku, Chiba 263-8522, Japan \\ ${ }^{3}$ Safety and Health Organization, Chiba University, 1-33 Yayoi-cho, Inage-ku, Chiba 263-8522, Japan
}

\begin{abstract}
Nitrogen-free phenol resin fiber was used to examine the effect of nitrogen-introduction via thermal chemical vapor deposition (CVD) using nitrogen-containing chemicals. In this study, a combination of heat treatment, steam activation, aniline CVD was conducted to prepare the nitrogen-doped activated carbon (AC) and the effective procedure was studied to enhance arsenic adsorption capacity. As a result, consecutive treatment of steam activation as pre-treatment, aniline CVD, steam activation for porous structure, and at least heat treatment was the best processing order for the preparation of ACs. Heat-treated samples demonstrated their robustness against steam activation; therefore heat treatment should be conducted as post treatment for effective CVD process. One of the samples which was prepared by this procedure, 8ST30-8ANL10-8ST50-9.5HT30 (sample \#5) showed $0.112 \mathrm{mmol} / \mathrm{g}$ of arsenate adsorption capacity, and it was at least $70 \%$ higher than that of any other prepared samples. To inspect the high adsorption capacity of this sample, the effect of solution $\mathrm{pH}$, pore structure parameters, elemental analysis, and Boehm titration was conducted comparing with the other prepared samples.
\end{abstract}

Keywords: Activated carbon fibers, Adsorption, Arsenate, Chemical vapor deposition, Phenol resin

\section{Introduction}

Arsenic, one of the toxic metallic contaminants, can be found in natural sulfidic minerals or sediments [1]. Arsenic is generally released into the water by global geochemical activities [2]. However, human activities such as mining, burning fossil fuels [1], and smelting [3] also release anthropogenic arsenic compounds. Arsenic contamination in water sources could affect water-related activities such as rice cultivation [4]. Main species of arsenic in groundwater are the inorganic form, as pentavalent under the aerobic condition and trivalent under anaerobic condition [5]. Arsenic in drinking water is one of the well-known carcinogens, especially trivalent arsenic was reported to be greater toxicity than pentavalent arsenic [1]. Oral ingestion of pentavalent arsenic also reduced into trivalent arsenic in the human cell causing various skin diseases including cancer [6].Therefore, the World Health Organization (WHO) has determined drinking water quality criteria to be $0.01 \mathrm{mg}-\mathrm{As} / \mathrm{L}$ or less because aqueous arsenic adversely affects human health [7].

To remove the excessive arsenic from water sources, oxidation
[8], flocculation and filtration [9], coprecipitation [10], and adsorption methods have been reported. Among these methods, adsorption needs simple operation process and does not create sludge as a waste [1]. Activated alumina [11], iron-coated adsorbents [12], ion exchange resin [13], and activated carbon [14] can be utilized as an adsorbent. Activated carbon is usually prepared from waste such as rice husks [11], coconut husks [15], and petroleum cokes [16], and the production costs would be cheaper than other adsorbents. In addition to the carbonaceous materials have stronger resistance heat and acid-resistant than other polymeric ion exchangers have, therefore activated carbon is more flexible than other adsorbents. The activated carbon is widely used for the adsorption of volatile organic compounds (VOCs) because of its porous structure and large specific surface area [17].

In our previous studies, heating and nitrogen-doping treatments increased the anion adsorption capacity of activated carbons. Heating activated carbon at $950^{\circ} \mathrm{C}$ for enhancing the $\pi$-electrons on the graphene layer [18] and forming quaternary nitrogen from pyridine type nitrogen by thermal decomposition were conducted
This is an Open Access article distributed under the terms of the Creative Commons Attribution Non-Commercial License (http://creativecommons.org/licenses/by-nc/3.0/) which permits unrestricted non-commercial use, distribution, and reproduction in any medium, provided the original work is properly cited.
Received May 23, 2019 Accepted September 26, 2019

${ }^{\dagger}$ Corresponding author

Email: ypha2000@naver.com

Tel: +81-43-290-3129 Fax: +81-43-290-3559

Copyright (C) 2020 Korean Society of Environmental Engineers 
[19]. We also conducted thermal chemical vapor deposition (CVD) for doping nitrogen onto the carbon surface [20]. Combination of the CVD, steam activation and thermal outgassing successfully enhanced the anion adsorption capacity [21]. In these studies, we used commercial activated carbon fibers (ACFs) which have 1.5 wt\% of nitrogen content for CVD treatment as a raw material. However, it was difficult to distinguish the nitrogen already present in the commercial ACFs from that introduced by the CVD process, in which both played an important role for enhancing anion adsorption capacity. Therefore, we prepared nitrogen-doped material using nitrogen-free phenol resin as a raw material to determine whether the introduced nitrogen could act as adsorption sites for anion adsorption in this study. Furthermore, we also determined the effective procedure for CVD treatment via comparison of surface properties and arsenate adsorption capacities. Because we demonstrated the combination of the CVD, steam activation, and thermal outgassing treatment to enhance the anion adsorption capacity, the optimal procedure has not been clarified in our previous study.

\section{Materials and Methods}

\subsection{Reagents}

All the reagents used in this study were analytical grade and used without purification. Phenol resin (Kynol Fiber KF-0270) was purchased from GunEi Chemical Industry Co., Ltd., Japan. The manufacturer describes this phenol resin as a novoloid fiber, and its carbon, hydrogen, nitrogen and oxygen conent are 76, 6, 0 and $18 \mathrm{wt} \%$, respectively. Phenol resin was dried at $110^{\circ} \mathrm{C}$ for $30 \mathrm{~min}$ before conducting treatments.

\subsection{Adsorbent Preparation}

All treatments were performed in a tubular reactor. Quartz tube was used as a reactor and it was $28 \mathrm{~mm}$ outer diameter $\times 24 \mathrm{~mm}$ inner diameter $\times 0.60 \mathrm{~m}$ length in size. All experimental methods were performed under a helium flow, and the initial amount of the phenol resin was $6 \mathrm{~g}$. Under these experimental conditions, we conducted heat treatment, steam activation, and thermal chemical vapor deposition for the phenol resin consecutively. For the heat treatment, samples were heated at $950^{\circ} \mathrm{C}$ for $30 \mathrm{~min}$. The main purpose of heat treatment is removing oxygen from the surface of ACs and quaternarization of surficial nitrogen. The samples treated in these processes were named as 9.5HT30. In steam activation step, 30 or $50 \mathrm{~mL}$ of distilled water was introduced at $800^{\circ} \mathrm{C}$. The flow rate was $0.5 \mathrm{~mL} / \mathrm{min}$. The samples treated in these processes were named as 8ST30 and 8ST50, respectively. Thermal chemical vapor deposition (CVD) was performed using aniline. The amount of the introduced aniline was $10 \mathrm{~mL}$, and the flow rate and temperature were also $0.5 \mathrm{~mL} / \mathrm{min}$ as well as the steam activation. The samples modified using thermal CVD process were named as 8ANL10. After the CVD process, the newly formed structure plugs the pore of activated carbon. Since the porous structure of AC is an important parameter of the adsorption capacity, we conducted steam activation after CVD as a post treatment to raise the specific surface area. All prepared samples prepared in this study were listed in Table 1 . We numbered each prepared sample and hereafter used these numbers for description.
Table 1. List of the Prepared Samples and Arsenic Adsorption Capacity (Initial Arsenate Concentration: $100 \mathrm{mg} / \mathrm{L}$, Initial Solution $\mathrm{pH}$ 7.0)

\begin{tabular}{lcc}
\hline $\begin{array}{l}\text { Sample } \\
\text { number }\end{array}$ & Sample name & $\begin{array}{c}\mathbf{Q}^{\mathbf{e}} \\
{[\mathbf{m m o l} / \mathbf{g}]}\end{array}$ \\
\hline$\# 0$ & Kynol Fiber & 0.000 \\
$\# 1$ & 9.5 HT30-8ST30 & 0.039 \\
$\# 2$ & $9.5 H T 30-8 S T 50$ & 0.047 \\
$\# 3$ & 9.5HT30-8ST30-8ANL10-9.5HT30-8ST50 & 0.039 \\
$\# 4$ & 8ST30-8ANL10-9.5HT30-8ST50 & 0.051 \\
$\# 5$ & 8ST30-8ANL10-8ST50-9.5HT30 & 0.112 \\
$\# 6$ & 9.5HT30 & 0.000 \\
$\# 7$ & 8ANL10-9.5HT30 & 0.000 \\
$\# 8$ & 8ANL10-8ST50-9.5HT30 & 0.066 \\
\hline
\end{tabular}

\subsection{Adsorption Studies}

The arsenate adsorption experiments were performed using $\mathrm{NaH}_{2} \mathrm{AsO}_{4} \cdot 7 \mathrm{H}_{2} \mathrm{O}$ aqueous solution. The initial concentration of arsenate was varied from 5 to $100 \mathrm{mg}-\mathrm{As}(\mathrm{V}) / \mathrm{L}$. In $30 \mathrm{~mL}$ Erlenmeyer flask, $30 \mathrm{mg}$ of prepared samples and $15 \mathrm{~mL}$ arsenate solution were added. The solution $\mathrm{pH}$ was measured with a $\mathrm{pH}$ meter (D-51, Horiba). Moreover, hydrochloric acid and sodium hydroxide were added to adjust the solution $\mathrm{pH}$. At the room temperature, the mixtures were agitated at $100 \mathrm{rpm}$ for $24 \mathrm{~h}$ to reach the equilibrium state. Arsenate concentration was determined by ion chromatograph (ICS-1100, Nippon Dionex KK), and adsorption amount at the equilibrium state was calculated by the following equation:

$$
Q_{e}=\frac{\left(C_{0}-C_{e}\right) v}{w}
$$

where $\mathrm{C}_{0}$ and $\mathrm{C}_{\mathrm{e}}$ represent the initial and the equilibrium arsenate concentrations $[\mathrm{mmol} / \mathrm{L}]$, respectively. $\mathrm{v}$ represents solution volume $[\mathrm{mL}]$ and $\mathrm{w}$ indicates the weight of adsorbent [mg].

To determine the optimal adsorption time, adsorption kinetics in aqueous condition were examined. One hundred mg of AC samples were added into $200 \mathrm{~mL}$ of $100 \mathrm{mg}-\mathrm{As} / \mathrm{L}$ solution. The mixture was agitated at $100 \mathrm{rpm}$ at room temperature, and residual concentration of arsenate at a certain time was sampled and examined. All experimental data were fitted to the following Eq. (2) and (3), which represent the pseudo-first-order and the pseudo-second-order kinetic model, respectively.

$$
\begin{gathered}
\frac{\mathrm{dQ}_{\mathrm{t}}}{\mathrm{dt}}=\mathrm{k}_{1}\left(\mathrm{Q}_{\mathrm{e}}-\mathrm{Q}_{\mathrm{t}}\right) \\
\frac{\mathrm{d} \mathrm{Q}_{\mathrm{t}}}{\mathrm{dt}}=\mathrm{k}_{2}\left(\mathrm{Q}_{\mathrm{e}}-\mathrm{Q}_{\mathrm{t}}\right)^{2}
\end{gathered}
$$

where $Q_{t}$ and $Q_{e}[\mathrm{mmol} / \mathrm{L}]$ represent the amount of adsorption at the certain time and equilibrium state, respectively. $\mathrm{k}_{1}[1 / \mathrm{h}]$ is pseudo-first order rate constant, and $\mathrm{k}_{2}[\mathrm{~g} / \mathrm{mmol} \mathrm{h}]$ is pseudo-second order rate constant.

The obtained experimental adsorption data were fitted to the Langmuir and Freundlich isotherm models. We applied the follow- 
ing equation as a Langmuir isotherm model.

$$
\frac{\mathrm{C}_{\mathrm{e}}}{\mathrm{Q}_{\mathrm{e}}}=\frac{1}{\mathrm{Q}_{\mathrm{m}}} \mathrm{C}_{\mathrm{e}}+\frac{1}{\mathrm{Q}_{\mathrm{m}} \mathrm{K}_{\mathrm{L}}}
$$

where $C_{e}$ represents the arsenate concentration at equilibrium state. $\mathrm{K}_{\mathrm{L}}[\mathrm{L} / \mathrm{mmol}]$ refers to the Langmuir isotherm constant. $\mathrm{Q}_{\mathrm{e}}$ and $\mathrm{Q}_{\mathrm{m}}$ $[\mathrm{mmol} / \mathrm{L}]$ are the adsorption capacity at the equilibrium and maximum adsorption capacity, respectively. Freundlich isotherm model can be written as the following equation:

$$
\mathrm{Q}_{\mathrm{e}}=\mathrm{K}_{\mathrm{F}} \mathrm{C}_{\mathrm{e}}^{1 / \mathrm{n}}
$$

where $K_{F}\left[(\mathrm{mmol} / \mathrm{g})(\mathrm{L} / \mathrm{mmol})^{1 / 1}\right]$ is the Freundlich isotherm constant, and $1 / \mathrm{n}$ is related to the heterogeneity of the surface [22].

\subsection{Adsorbent Properties}

Pore characteristics of the samples were determined by BET measurement using $\mathrm{N}_{2}$ adsorption/desorption isotherms at liquid $\mathrm{N}_{2}$ temperature (BELSORP-mini II, Microtrac BEL). Prepared samples were outgassed at $300^{\circ} \mathrm{C}$ for an hour before the analysis. Using this method, the specific surface area $\left(\mathrm{S}_{\mathrm{BET}}\right)$ and average pore size $\left(\mathrm{D}_{\text {avg }}\right)$ of the samples were calculated. The total pore volume $\left(\mathrm{V}_{\text {total }}\right)$ was calculated from the maximum nitrogen adsorption capacity at a relative pressure of 0.990 . The micropore volume $\left(\mathrm{V}_{\text {micro }}\right)$ was calculated by SPE method using $\alpha_{\text {s }}$ plots [23].

Elemental composition of the prepared samples was determined by CHN elemental analyzer (PE2400II, Perkin Elmer). We assumed that the prepared samples are composed of carbon, hydrogen, nitrogen and oxygen. Oxygen content was calculated by balance.

Boehm titration method was used to determine the amount of surface basic functional groups on the prepared activated carbon samples. Solutions of $0.1 \mathrm{~mol} / \mathrm{L} \mathrm{NaOH}$ and $0.1 \mathrm{~mol} / \mathrm{L} \mathrm{HCl}$ were prepared, and $25 \mathrm{~mL}$ of each solution and $200 \mathrm{mg}$ of each sample were added in a $100 \mathrm{~mL}$ Erlenmeyer flask. The flasks were agitated for $4 \mathrm{~d}$ at $25^{\circ} \mathrm{C}$. After the shaking process, $5 \mathrm{~mL}$ of each solution was sampled and titrated with $0.05 \mathrm{~mL} \mathrm{HCl}$. In the case of the $0.1 \mathrm{~mol} / \mathrm{L} \mathrm{HCl}, 10 \mathrm{~mL}$ of $0.1 \mathrm{~mol} / \mathrm{L} \mathrm{NaOH}$ was added to perform back titration.

\section{Results and Discussion}

\subsection{Adsorption Kinetics of Arsenate}

To compare the kinetic properties between non-CVD and CVD-treated samples, we choose samples \#1 and \#5. Fig. 1 and Table 2 display the results. Sample \#1, which was prepared by steam activation and heat treatment, and its experimental results, followed

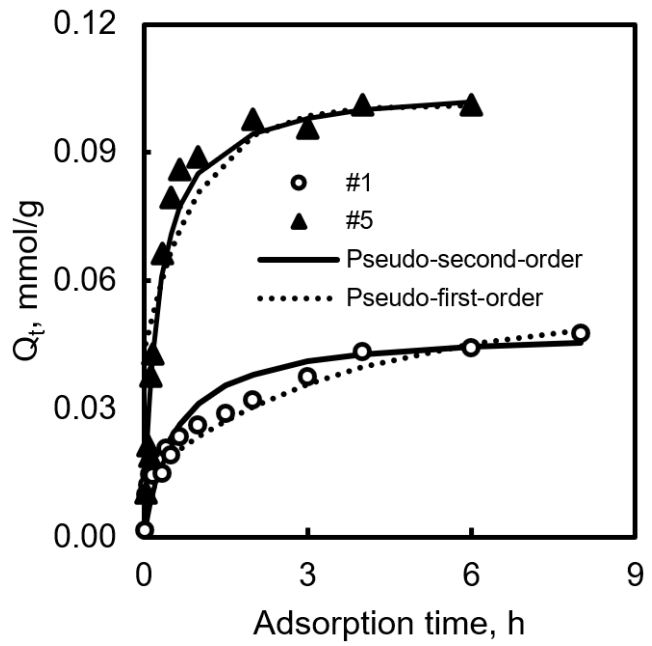

Fig. 1. Adsorption kinetics of the prepared samples for arsenate adsorption. Solid and dotted lines indicate fitting curves to pseudo-first and pseudo-second order models, respectively. (Initial arsenate concentration: $100 \mathrm{mg} / \mathrm{L}$, initial solution $\mathrm{pH} 7.0$ )

the pseudo-second-order equation. It required $4 \mathrm{~h}$ to reach the equilibrium state. In the case of sample \#5, it also followed the pseudo-second-order equation. Pseudo-first order model suggests that the rate-limiting step could be considered as a collision between adsorbent and adsorbate, and pseudo-second order model represents pore diffusion. CVD-treated samples also required $4 \mathrm{~h}$ to reach the equilibrium state, because of its high rate constant $\left(k_{2}\right)$, and the amount of adsorption increased faster in the first $2 \mathrm{~h}$ than non-CVD samples [24].

\subsection{Effect of $\mathrm{pH}$ on the Arsenate Adsorption on the Activated Carbons}

Fig. 2 describes the relationship between the equilibrium $\mathrm{pH}$ and arsenate adsorption capacity. The results pointed out that the $\mathrm{pH}_{\mathrm{e}}$ 7 was the best $\mathrm{pH}$ condition for arsenate adsorption. We adjusted the solution $\mathrm{pH}$ for arsenic adsorption to 6.8-7.2 in further experiments. When the $\mathrm{pH}_{\mathrm{e}}$ was greater than 11 , the adsorption capacities reached zero, whereas the adsorption capacity did not decrease to zero at $\mathrm{pH}_{\mathrm{e}} 3$. The $\mathrm{pK}_{\mathrm{a}}$ of $\mathrm{H}_{3} \mathrm{AsO}_{4}$ is 2.19, 6.94, and 11.5. When the $\mathrm{pH}_{\mathrm{e}}$ is $11, \mathrm{HAsO}_{4}^{2-}$ and $\mathrm{AsO}_{4}^{3-}$ are the main species in aqueous solution. At $\mathrm{pH} \mathrm{3}$, the dominant species of arsenate are $\mathrm{H}_{3} \mathrm{AsO}_{4}$ and $\mathrm{H}_{2} \mathrm{AsO}_{4}^{-}$. In our preliminary study [14], anion adsorption mechanism was based on the electrostatic attraction and ion exchange between adsorbent and adsorbate. Therefore, when the $\mathrm{pH}$ is lower than 4, the neutral form of arsenate exists in the solution, and it could not be effectively adsorbed onto the adsorbent.

\begin{tabular}{|c|c|c|c|c|c|c|}
\hline \multirow{2}{*}{ Sample } & \multicolumn{3}{|c|}{ Pseudo-first order } & \multicolumn{3}{|c|}{ Pseudo-second order } \\
\hline & $\mathrm{Q}_{\mathrm{e}}[\mathrm{mmol} / \mathrm{g}]$ & $k_{1}[1 / h]$ & $\mathbf{R}^{2}$ & $\mathrm{Q}_{\mathrm{e}}[\mathrm{mmol} / \mathrm{g}]$ & $\mathbf{k}_{2}[\mathrm{~g} / \mathbf{m m o l} \mathbf{h}]$ & $\mathbf{R}^{2}$ \\
\hline$\# 1$ & 0.038 & 0.273 & 0.957 & 0.049 & 37.0 & 0.984 \\
\hline \#5 & 0.058 & 1.04 & 0.932 & 0.106 & 38.0 & 0.998 \\
\hline
\end{tabular}

Table 2. Calculated Pseudo-First and Pseudo-Second Order Kinetics Parameters for Arsenate Adsorption 
Moreover, we added hydrochloric acid for adjusting solution $\mathrm{pH}$, and $\mathrm{Cl}^{-}$would be a competitive anion with arsenate. On the other hand, when the solution $\mathrm{pH}$ is higher than 4 , the dominant species of arsenate are anion form; therefore the anionic arsenate would be appropriate for adsorption. As the experimental results point out, the adsorption capacity was increased when the solution $\mathrm{pH}$ rose up to 7 . If the solution $\mathrm{pH}$ is greater than 7 , solution $\mathrm{OH}^{-}$ concentration also increases. Kwok [25] reported that the excessive $\mathrm{OH}^{-}$showed a negative effect on arsenic adsorption because the ion exchange occurred between $\mathrm{OH}^{-}$and anionic arsenates. Moreover, the repulsive interaction between the negatively charged arsenic ion and negatively charged AC surface occurs at the basic $\mathrm{pH}$ range. Hence, the adsorption capacity decreased when the $\mathrm{pH}_{\mathrm{e}}$ increased at the $\mathrm{pH}$ range 7-11. Comparing these two competitive ions, $\mathrm{OH}^{-}$would have stronger negative effects on arsenate adsorption. In conclusion, when the $\mathrm{pH}_{\mathrm{e}}$ is lower than 7 , the adsorption capacity strongly depended on the concentration of anionic arsenate form. However, the hydroxide concentration was an important factor when the $\mathrm{pH}_{\mathrm{e}}$ is bigger than 7 .

\subsection{Adsorption Isotherm}

Table 1 describes the adsorption capacity of the prepared samples for arsenate adsorption. The adsorption isotherms for prepared samples are shown in Fig. 2. We choose the best samples from non-CVD samples and CVD-treat samples to depict isotherm. Table 3 shows the calculated Langmuir and Freundlich parameters. Coefficient of determination $\mathrm{R}^{2}$ indicated that the Langmuir isotherm was the best fitting.

\subsection{Adsorbent Properties}

Porous structural parameters of prepared samples are shown in Table 4. Samples \#1, \#2 and \#6 pointed out that the specific surface area depended on the amount of the introduced distilled

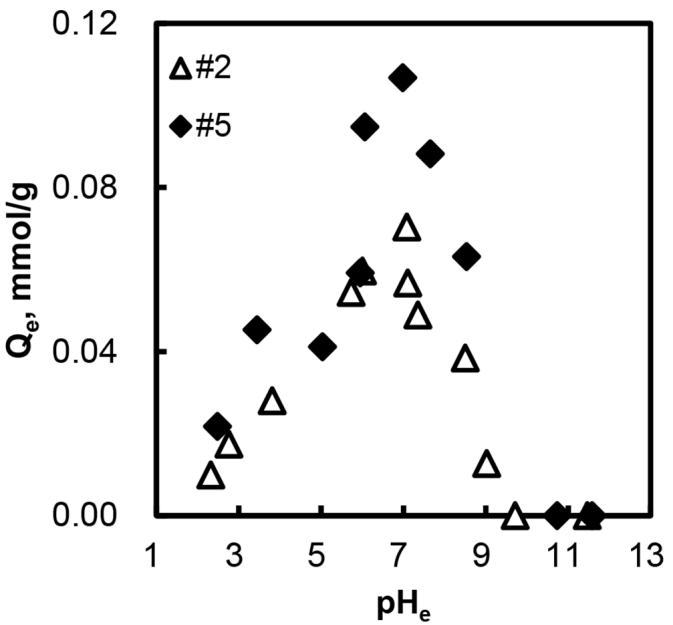

Fig. 2. Effect of equilibrium $\mathrm{pH}$ on arsenate adsorption. (Initial arsenate concentration: $100 \mathrm{mg} / \mathrm{L}$ )

water. Sample \#7 indicated $S_{\mathrm{BET}}$ of only $4 \mathrm{~m}^{2} / \mathrm{g}$, implying that aniline CVD process successfully formed a new surface on the precursor. Incidentally, the order of heat treatment and steam activation could affect the surficial property; therefore we also prepared samples, which were sample \#4 and \#5. Sample \#4 had $\mathrm{S}_{\mathrm{BET}}$ of $936 \mathrm{~m}^{2} / \mathrm{g}$, which was only $71 \%$ of sample \#5. From this result, heat treatment enhances the robustness against the activation process, and therefore heat treatment should be conducted finally for the effective activation process. $\mathrm{Q}_{\mathrm{e}} / \mathrm{S}_{\mathrm{BET}}$ was also calculated for comparing adsorption effectiveness. CVD-treated samples (samples \#3-\#5) showed at least $18 \%$ higher $\mathrm{Q}_{\mathrm{e}} / \mathrm{S}_{\mathrm{BET}}$ value than that for non-CVD treated samples (samples \#1 and \#2). In the case of sample \#8, steam activation was not conducted as a pretreatment, showing that nitrogen doping would not be conducted properly.

Table 3. Calculated Langmuir and Freundlich Isotherm Parameters for Arsenate Adsorption

\begin{tabular}{|c|c|c|c|c|c|c|}
\hline \multirow{2}{*}{ Sample } & \multicolumn{3}{|c|}{ Langmuir isotherm } & \multicolumn{3}{|c|}{ Freundlich isotherm } \\
\hline & $\mathrm{Q}_{\mathrm{m}}[\mathrm{mmol} / \mathrm{g}]$ & $\mathrm{K}_{\mathrm{L}}[\mathrm{L} / \mathbf{m m o l}]$ & $\mathbf{R}^{2}$ & $\mathrm{~K}_{\mathrm{f}}\left[(\mathrm{mmol} / \mathrm{g})(\mathrm{L} / \mathrm{mmol})^{1 / \mathrm{n}}\right]$ & $1 / \mathbf{n}$ & $\mathbf{R}^{2}$ \\
\hline$\# 2$ & 0.07 & 25 & 0.991 & 0.08 & 0.32 & 0.717 \\
\hline \#5 & 0.12 & 6.4 & 0.984 & 0.12 & 0.45 & 0.845 \\
\hline
\end{tabular}

Table 4. Porous Structural Parameters of the Prepared Samples

\begin{tabular}{|c|c|c|c|c|c|}
\hline Sample number & $\mathrm{S}_{\mathrm{BET}}\left[\mathrm{m}^{2} / \mathrm{g}\right]$ & $\mathrm{V}_{\text {total }}\left[\mathrm{cm}^{3} / \mathrm{g}\right]$ & $\mathrm{V}_{\text {micro }}\left[\mathrm{cm}^{3} / \mathrm{g}\right]$ & $\mathbf{D}_{\text {avg }}[\mathrm{nm}]$ & $\mathrm{Q}_{\mathrm{e}} / \mathrm{S}_{\mathrm{BET}}\left[10^{-5} \mathrm{mmol} / \mathrm{m}^{2}\right]$ \\
\hline$\# 0$ & 2 & 0.002 & 0.001 & 3.17 & 0.00 \\
\hline$\# 1$ & 966 & 0.385 & 0.382 & 1.59 & 4.04 \\
\hline$\# 2$ & 1,010 & 0.405 & 0.402 & 1.60 & 4.65 \\
\hline$\# 3$ & 708 & 0.292 & 0.288 & 1.65 & 5.51 \\
\hline$\# 4$ & 936 & 0.380 & 0.378 & 1.63 & 5.45 \\
\hline$\# 5$ & 1,310 & 0.547 & 0.543 & 1.67 & 8.55 \\
\hline$\# 6$ & 405 & 0.006 & 0.002 & 0.06 & 0.00 \\
\hline$\# 7$ & 4 & 0.004 & 0.003 & 3.63 & 0.00 \\
\hline \#8 & 1,363 & 0.576 & 0.574 & 1.69 & 4.84 \\
\hline
\end{tabular}


Table 5. Elemental Composition and Total Basic Functional Groups of the Prepared Samples

\begin{tabular}{lccccc}
\hline Sample number & $\mathbf{C}$ [wt\%] & H [wt\%] & N [wt\%] & $\mathbf{O}^{*}$ [wt\%] & Basic functional groups [mmol/g] \\
\hline$\# 1$ & 94 & 0.57 & 0.27 & 5.6 & 0.24 \\
$\# 2$ & 93 & 0.54 & 0.24 & 5.8 & 0.31 \\
$\# 3$ & 93 & 0.46 & 0.69 & 6.1 & 0.07 \\
$\# 4$ & 94 & 0.53 & 1.3 & 3.9 & 0.33 \\
$\# 5$ & 89 & 0.51 & 0.52 & 10 & 0.14 \\
$\# 6$ & 91 & 0.40 & 0.23 & 7.9 & - \\
$\# 8$ & 97 & 0.31 & 1.8 & 0.97 & - \\
\hline
\end{tabular}

${ }^{*}$ calculated by balance

Table 5 shows the elemental composition of the prepared samples. Nitrogen contents of samples \#1 and \#2, which were not treated with aniline, were $0.24 \mathrm{wt} \%$ and $0.27 \mathrm{wt} \%$, respectively, while those of all CVD-treated samples (\#3-\#5, \#8) were at least $37 \%$ greater than those of samples \#1 and \#2. In the case of sample \#3, the specific surface area was the lowest among the CVD-treated samples, and nitrogen content was $53 \%$ of sample \#4. These results exhibited that the heat treatment as a pre-treatment for CVD was not appropriate. Containing high specific surface area is important for precursors of the CVD process because the purpose of steam activation as a pre-treatment is to increase the contact area between the chemical vapor and the sample surface. Nitrogen content of sample \#5 and \#8 demonstrated this idea, because sample \#5 showed $41 \%$ higher nitrogen content than sample \#8, and the difference between samples \#5 and \#8 is only the steam activation as a pre-treatment. Therefore, the high specific surface area is an important factor for the precursor in the CVD process. In the same way, the newly formed nitrogen-rich surface by aniline would become hard to be activated using the steam after the heat treatment. Sample \#4 showed the highest nitrogen content, but the specific surface area was $71 \%$ of sample \#5 because of that reason. To sum up, 8ST30-8ANL10-8ST50-9.5HT30 (sample \#5) was the most effective order for preparing thermal CVD-treated activated carbon from phenol resin as a raw material.

Total basic functional groups of steam-treated samples (samples \#1-\#5) were shown in Table 5. In our previous study, the high amount of basic functional groups on the activated carbon was the most important parameter for effective arsenate adsorption [14]. As examples of the basic functional groups, Ota et al. [18] reported that $\pi$-electrons on the graphene layer can attract some protons resulting in a slight increase of adsorption site. This adsorption mechanism was also observed in this study. The initial solution $\mathrm{pH}$ was 6.94 at the initial arsenate concentration of $100 \mathrm{mg}-\mathrm{As}(\mathrm{V}) / \mathrm{L}$, and the equilibrium $\mathrm{pH}$ for samples \#2 and \#5 was 7.21 and 7.29, respectively. Moreover, pyridinic nitrogen (N-6), pyrrolic nitrogen (N-5) and amine groups could become positively charged adsorption sites below certain $\mathrm{pH}$ which depends on their $\mathrm{p} K_{\mathrm{a}}$, whereas the quaternary nitrogen (N-Q) always exists as positively charged sites [20, 26]. Furthermore, oxygen-containing basic groups generated by thermal decomposition of oxygenated acidic groups could act as basic sites [27]. Hence, these potential adsorption sites could be measured by Boehm titration except N-Q. But the
Boehm titration is using $0.1 \mathrm{M} \mathrm{HCl}$ to neutralize the basic functional groups. Therefore, Boehm titration is hard to differentiate among weak and strong nitrogen-containing basic functional groups, oxygen-containing basic surface functional groups and $\pi$-electrons on the graphene layer [27]. The number of basic functional groups increased between samples \#1 and \#2, and adsorption capacity also increased when the specific surface area increased. It could be assumed that large specific surface area accommodated more protons and it works as adsorption sites for arsenate. At the acidic $\mathrm{pH}_{\mathrm{e}}$ range of 2-6, the adsorption capacity of CVD-treated samples would be higher than non-CVD samples because N-5 and N-6 might be formed by the CVD process. Also, in the case of sample \#5, it showed the highest oxygen content than other samples. It means that sample \#5 has the highest oxygen-containing acidic or basic functional groups. However, there was no significant difference in adsorption capacity for samples \#2 at the acidic $\mathrm{pH}$ range. Oxygen-containing acidic functional groups are known as electron withdrawing groups, and excessive acidic oxygenated functional groups diminish the $\pi$-electrons on the graphene layer. Sample \#5 showed the lower number of basic functional group than that of non-CVD samples, but it showed the highest oxygen content. In conclusion, the oxygen in the CVD-treated samples could mainly exist as oxygen-containing acidic functional groups. This result also explains that sample \#3 showed the lowest basic functional groups, but their oxygen content was nearly the same as non-CVD samples.

\subsection{Comparisons of Arsenic Adsorption Capacities of Various Adsorbents}

Comparisons of arsenic(V) adsorption capacities of the various adsorbents are shown in Table 6. In this study, we prepared activated carbon derived from phenol resin and showed better adsorption capacity than that of our previous study [14]. Moreover, we also showed that the amount of basic functional groups was not always related to arsenic adsorption at $\mathrm{pH} 7$ which was optimal $\mathrm{pH}$ condition for arsenic adsorption. In addition, if the precursor is nitrogen-rich and that nitrogen has robustness against heat, it is expected to enhance the arsenic adsorption capacity. In a recent study, activated carbons which were loaded with other materials on the surface such as iron particles are mainly used for arsenic(V) removal [29, 31]. Zhang et al. [29] stated that the activated carbon fibers were better supporting matrix for iron oxides. We used fiber-type phenol 
Table 6. Comparison of the Arsenate $(\mathrm{V})$ Adsorption Capacities of the Various Adsorbents

\begin{tabular}{|c|c|c|c|c|c|}
\hline Adsorbent & $\begin{array}{c}\mathrm{Qe}_{\mathrm{e}} \\
{[\mathrm{mmol} / \mathrm{g}]}\end{array}$ & $\begin{array}{l}\text { Initial concentration } \\
{[\mathrm{mg} / \mathrm{L}]}\end{array}$ & pH & $\begin{array}{l}\text { Adsorbent dosage } \\
{[\mathrm{g} / \mathrm{L}]}\end{array}$ & Ref. \\
\hline $\begin{array}{l}\text { Activated carbon derived from cocoa pod husk and } \\
\text { activated by } \mathrm{ZnCl}_{2}(\mathrm{CPH}-21)\end{array}$ & 0.002 & 0.1 & $6-7$ & 0.5 & [28] \\
\hline Commercial ACF cloths (RACF) & 0.007 & 2 & 4.0 & $0.6-0.7$ & [29] \\
\hline $\begin{array}{l}\text { Granular activated carbon made from bituminouscoal } \\
\text { (Aquacarb 207EA) }\end{array}$ & 0.031 & 10 & 7.7-8.3 & 2 & [30] \\
\hline $\begin{array}{l}\text { Ball-milled iron doped activated carbon made from } \\
\text { phenolic resin beads (PBFe-BM-Act) }\end{array}$ & 0.076 & 10 & 6.5 & 5.0 & [31] \\
\hline $\begin{array}{l}\text { Bamboo-based and bead-shaped activated carbon } \\
\text { treated by heat treatment (BAC-10OG) }\end{array}$ & 0.070 & 100 & 7.6 & 2.5 & [14] \\
\hline $\begin{array}{l}\text { Nitrogen-doped activated carbon from phenol resin } \\
\text { (8ST30-8ANL10-8ST50-9.5HT30, \#5) }\end{array}$ & 0.112 & 100 & $6.8-7.2$ & 2.0 & This study \\
\hline
\end{tabular}

resin as a precursor. Furthermore, non-CVD and CVD-treated samples were followed by the Langmuir isotherm model and pseudo-second order kinetic model. This result reveals that CVD processed samples maintain the properties of adsorbent as activated carbon fiber. Therefore, by using various ACFs containing nitrogen as precursors and using the optimized treatment method (sample \#5) which is demonstrated in this study, it is expected that the adsorption capacity can be enhanced through these additional surface modifications.

\section{Conclusions}

In this study, we conducted heat treatment, steam activation, and thermal CVD to prepare nitrogen-doped AC, and examined the adsorption capacity of the samples to elucidate the most effective preparation order. 8ST30-8ANL10-8ST50-9.5HT30 (sample \#5) was the optimal procedure for aniline CVD to prepare adsorbent for arsenic adsorption. Sample \#5 showed $0.112 \mathrm{mmol} / \mathrm{g}$ of arsenate adsorption capacity, and it was at least $70 \%$ higher than that of any other prepared samples. The surface properties which played the most decisive role in the maximum arsenic adsorption amount in this study were the specific surface area and the nitrogen content. $\mathrm{Q}_{\mathrm{e}} / \mathrm{S}_{\mathrm{BET}}$ value of CVD-treated samples represented that the newly formed nitrogen on the surface would enhance adsorption capacity. In addition, both non-CVD and CVD-treated samples maintained their adsorption mechanisms between activated carbon fibers and arsenic. To sum up, by using nitrogen-rich ACFs as precursors and conducting the optimized treatment method (sample \#5), it is expected that the adsorption capacity can be enhanced through additional surface modifications.

\section{Acknowledgements}

The authors would like to thank the center for analytical instrumentation CHIBA UNIV for supporting elemental analysis. Grateful thanks are also extended to Prof. Dr. Fumio IMAZEKI, the head of Safety and Health Organization, Chiba University, for the financial support on our study.

\section{References}

1. Shankar S, Shanker U, Shikha. Arsenic contamination of groundwater: A review of sources, prevalence, health risks, and strategies for mitigation. Sci. World J. 2014;304524:1-18.

2. Pontius F, Brown K, Chen C. Health implications of arsenic in drinking water. J. Am. Water Works Assoc. 1994;86:52-63.

3. Axelson O, Dahlgren E, D Jansson C, Rehnlund S. Arsenic exposure and mortality: A case-referent study from a Swedish copper smelter. J. Occup. Environ. Med. 1978;35:8-15.

4. Kwon J, Nejad Z, Jung M. Arsenic and heavy metals in paddy soil and polished rice contaminated by mining activities in Korea. CATENA 2017;148;92-100.

5. Cullen W, Reimer K. Arsenic speciation in the environment. Chem. Rev. 1989;89:713-764.

6. Hall A. Chronic arsenic poisoning. Toxicol. Lett. 2002;123:69-72.

7. World Health Organization. Guidelines for drinking-water quality. 2011.

8. Zaw M, Emett M. Arsenic removal from water using advanced oxidation processes. Toxicol. Lett. 2002;133:113-118.

9. Han B, Runnells T, Zimbron J, Wickramasinghe R. Arsenic removal from drinking water by flocculation and microfiltration. Desalination 2002;145:293-298.

10. Jia Y, Demopoulos G. Co precipitation of arsenate with iron(III) in aqueous sulfate media: Effect of time, lime as base and co-ions on arsenic retention. Water. Res. 2008;42:661-668.

11. Bishnoi N, Bajaj M, Sharma N, Gupta A. Adsorption of Cr(VI) on activated rice husk carbon and activated alumina. Bioresour. Technol. 2004;91:305-307.

12. Payne K, Abdel-Fattah T. Adsorption of arsenate and arsenite by iron-treated activated carbon and zeolites: Effects of $\mathrm{pH}$, temperature, and ionic strength. J. Environ. Sci. Health A 2005;40:723-749

13. Ficklin W. Separation of arsenic(III) and arsenic(V) in ground 
waters by ion-exchange. Talanta 1983;30:371-373.

14. Amano Y, Matsushita Y, Machida M. Arsenic adsorption by activated carbon with different amounts of basic sites under different solution $\mathrm{pH}$ and coexistent ions. Sep. Sci. Technol. 2014;49:345-353.

15. Talat M, Mohan S, Dixit V, Singh D, Hasan S, Srivastava O. Effective removal of fluoride from water by coconut husk activated carbon in fixed bed column: Experimental and breakthrough curves analysis. Groundw. Sustain Dev. 2018;7:48-55.

16. Jang E, Choi S, Hong S, Shin S, Lee K. Development of a cost-effective $\mathrm{CO}_{2}$ adsorbent from petroleum coke via $\mathrm{KOH}$ activation. Appl. Surf. Sci. 2018;429:62-71.

17. Das D, Gaur V, Verma N. Removal of volatile organic compound by activated carbon fiber. Carbon 2004;42:2949-2962.

18. Ota K, Amano Y, Aikawa M, Machida M. Removal of nitrate ions from water by activated carbons (ACs)-Influence of surface chemistry of ACs and coexisting chloride and sulfate ions. Appl. Surf. Sci. 2013;276;838-842.

19. Sakamoto T, Amano Y, Machida M. Phosphate ion adsorption properties of polyacrylonitrile (PAN) activated carbon fiber. J. Fiber Sci. Technol. 2017;73:222-228.

20. Machida M, Yoo P, Amano Y. Adsorption of nitrate from aqueous phase onto nitrogen-doped activated carbon fibers (ACFs). SN. Appl. Sci. 2019;1;323.

21. Yoo P, Amano Y, Machida M. Adsorption of nitrate in aqueous solution on nitrogen-doped activated carbon fibers prepared by chemical vapor deposition. Korean J. Chem. Eng. 2018;35: 2468-2473.

22. Lorenc-Grabowska E, Gryglewicz G, Diez M. Kinetics and equilibrium study of phenol adsorption on nitrogen-enriched acti- vated carbons. Fuel 2013;114;235-243.

23. El-Merraoui M, Aoshima M, Kaneko K. Micro pore size distribution of activated carbon fiber using the density functional theory and other methods. Langmuir 2000;16:4300-4304.

24. Wang S, Li H. Kinetic modeling and mechanism of dye adsorption on unburned carbon. Dyes Pigm. 2007;72:308-314.

25. Kwok K, Koong L, Ansari T, Mckay G. Adsorption/desorption of arsenite and arsenate on chitosan and nanochitosan. Environ. Sci. Pollut. Res. 2018;25:14734-14742.

26. Bitter J, van Dommele S, de Jong K. On the virtue of acid-base titrations for the determination of basic sites in nitrogen doped carbon nanotubes. Catal. Today 2010;105;61-66.

27. Tessmer C, Vidic R, Uranowski L. Impact of oxygen-containing surface functional groups on activated carbon adsorption of phenols. Environ. Sci. Technol. 1997;31:1872-1878.

28. Cruz G, Pirilä M, Huuhtanen M, Carrión L, Alvarenga E, Keiski R. Production of activated carbon from cocoa (Theobroma cacao) pod husk. J. Civil. Environ. Eng. 2012;2;1-6.

29. Zhang S, Li X, Chen J. Preparation and evaluation of a magnetite-doped activated carbon fiber for enhanced arsenic removal. Carbon 2010;48;60-67.

30. Natale F, Erto A, Lancia A, Musmarra D. Experimental and modeling analysis of $\mathrm{As}(\mathrm{V})$ ions adsorption on granular activated carbon. Water Res. 2008;42;2007-2016.

31. Sharma A, Verma N, Sharma A, Deva D, Sankararamakrishnan $\mathrm{N}$. Iron doped phenolic resin based activated carbon micro and nanoparticles by milling: Synthesis, characterization and application in arsenic removal. Chem. Eng. Sci. 2010;65; 3591-3601. 